\title{
Gender Positioning in Education: A Critical Image Analysis of ESL Texts
}

\section{Peter Giaschi}

\begin{abstract}
This article is adapted from a project report prepared for the author's MA in Education, the objective being to report the use of an adapted analytical technique for examining the images contained in contemporary ESL textbooks. The point of departure for the study was the identification of the trend in mass-market ESL materials from textual to visual communication, a trend discussed in the text. Together with this semantic shift, a political-economic agenda has been identified in the existence of organizations such as the British Council; the objective of the analysis was to discover whether the increasingly predominant images used in ESL texts convey a particular vision of and/or positioning of gender reality as part of a wider-reaching agenda. The article provides background to the evolution of critical image analysis, followed by a rationale for the project based on the current realities of the global ESL market. There follows an outline of the data selected for analysis and the results of the image interrogation. The article concludes with a brief discussion of the ramifications of the study and the potential for further research work.
\end{abstract}

Over the past 60 years the spread of the English language throughout the world has become one of the central facts of education. According to Crystal (1988), the number of mother-tongue speakers of the language in 1985 was estimated at between 320 and 377 million, but the number of people using English as a second or a foreign language could only be guessed at: any where between 100 and 1,000 million. Ten years later Mercer and Swann (1996) estimated the number of ESL/EFL speakers at between 250 million and 1.3 billion speakers. At the outset this expansion was driven primarily by the British Council, a body formed in 1935 with the stated objective of promoting "cultural understanding" (Pennycook, 1994, p. 146) but which many have argued was more political-economic in nature (Pennycook; Coombs, 1988). Pennycook provides a thorough examination of the Council as the prototypical global ESL franchiser and as an instrument for "the dissemination of British ideas" (British Council, 1959-1960); it is essential to the scope of this article to emphasize this economic and political impetus: Pennycook uses Economic Intelligence Unit figures to put the 1988 value of the ESL/EFL industry in the United Kingdom alone at $£ 6.25$ billion (today approx. $\$ 20$ billion Can.), a figure that has surely grown since. These numbers illustrate both the number of people affected by the flow of ESL teaching materials from English-speaking cultures and the fundamental link between 
private industry and an ostensibly philanthropic far-reaching government agency. In the current study I investigated whether or what "cultural propaganda" is being disseminated today through ESL teaching materials originating from the UK, with the expectation that similar studies will be carried out in the other principal "home" ESL markets (Canada, the United States, Australia, etc.).

\section{Literature}

There is a curious reverse nature to the production of materials for the teaching of English as a second language: the materials themselves, produced in or by one culture and in context-specific conditions, are often used and absorbed in a sometimes radically different context with different sociopolitical and cultural realities, including gender roles and subsequent empowerment or oppression. Thus exposure to "British culture," for example, becomes an integral part of the process of learning the language and is often an expressed objective of the materials themselves. As seen above, the British Council exists for just this reason. ${ }^{1}$ The hidden agenda in such materials becomes clear when one views how different cultures might react to, in this instance, "British reality." For example, Ellis (1990) argues that Western-produced textbooks are ethnocentric and lists the ad infinitum ways that UK ESL materials manage to offend Muslim sensibilities.

This "instruction by images over distance" is a relatively recent phenomenon in ESL education, but has been studied in detail by Pennycook (among others) in The Cultural Politics of English as an International Language (1994). In Pennycook's references are works by Schenke (1991), who analyzes ESL and feminist pedagogy, and Mukherjee (1986), whose work deconstructs the imperialist elements of British Council activity. Frequent reference is made below to Fairclough's (1989) Language and Power and Berger's (1972) Ways of Seeing, both believed to be essential in examining gender positioning through the use of images and text. Fairclough and Berger use the term positioning in a quite literal way: individuals or groups of individuals are positioned by discourse as "inherently inferior," "in control," "weak," "strong," and so forth. Berger focuses principally on the positioning of women as objects to be possessed and of men as objects of envy; Fairclough examines various facets of contemporary culture as expressed through media and other discourses. Although the bulk of the referenced material is British in origin, it is arguable that both the nature of the Internet and the ESL industry itself render national borders somewhat superfluous; most papers or documents referenced here are available on the Web. Moreover, I was required to use American Streamline (Hartley \& Vine, 1979) by an ESL school in Tokyo, a text published by Oxford University Press and targeted at the US ESL market. Oxford University Press itself is present in every principal ESL market, including Canada and the US, and has followed the British Council in its forays into "developing" nations. In other words, at a global market level it is becoming 
increasingly irrelevant to speak of publishers as being British or US when, like the Internet, they are simultaneously nowhere and everywhere.

\section{Why Images?}

While the ESL industry has been revolutionizing educational realities in numerous countries all over the world, a revolution has taken place in the ESL materials industry itself; as Prodromou (1988) puts it, in the 1970s "the texts went technicolor." Increasingly, focus was placed on the visual presentation of the ESL textbook, as opposed to the grammatical or textual content. A concrete demonstration of this can be found in texts from different periods: O'Neill's (1970) English in Situations, published by Oxford University Press and described by the author as being designed for "normal intermediate courses," is 200 pages long and includes one image, a graph illustrating the use of the present perfect tense; Soar and Soar's (1996) New Headway Intermediate, again published by Oxford University Press, is 159 pages long and contains more than 260 images, most of them photographs. ${ }^{2}$ Clearly the focus has shifted; images have become an integral component of the presentation of the language and, as noted above, not only the language, but also the culture.

\section{Rationale}

Students of ESL may find it difficult or impossible to challenge the hidden positioning in the materials provided them (sold to them) for their English classes. The teacher-student dynamic ensures that they have been positioned as "the inferior," a dynamic that is discussed by Fisher (1994) among others; the students also often live in economic realities that predicate that everything Western is somehow connected with success. Although doubtless many ESL students study the language out of natural aptitude and/or desire and are critically engaged with their texts, it is also incontestable that for many others the English language has been, as Achebe (1975) puts it, "forced down their throats" through socioeconomic circumstances. Thus any analysis of the positioning contained in the ESL images will also find its rationale and (one hopes) initial positive impact in the conduit of ESL: the teachers themselves. Although the ESL profession is undoubtedly populated with caring and critically aware career teachers, it is also inevitable that with only a four-week investment needed to obtain some "teaching certificates," many take advantage of the global demand for ESL teachers to visit otherwise unavailable destinations while being paid for their travel..$^{3}$ It is clear that at least some of these newly "certified" teachers may not be committed to the work per se or concerned with the integrity of the materials. ESL teacher training has become a worldwide industry in itself, with myriad certificates available from any number of institutions including the British Council's RSA-Cambridge programs (CELTA, etc.), TESOL, various TOEFL certificates, and many other "training" groups providing certificates to mother- 
tongue English speakers that "qualify" them to teach ESL. It seems misguided to place three- or four-week certification courses on the same level with more intensive, long-term teacher preparation at an interpersonal (not to mention intercultural) level. Further, although efforts are underway in some markets to ensure teacher preparation (e.g., TESL Canada's National Recognition Standards project) the publication of the texts used in most ESL classrooms worldwide remains in the hands of a surprisingly small number of multinationals (see below). ESL teachers, whose only other qualification may be that they were born in an English-speaking environment, face the possibility of becoming the medium for any positioning integrated in the materials provided for them without their being fully aware of it. It seems opportune to make clear and available to ESL teachers how ideologies are being packaged and presented to them and how they themselves may be positioned: "People internalize what is socially produced and made available to them, and use this ... to engage in their social practice" (Fairclough, 1989, p. 24).

The nature of the images themselves provided further rationale for the project (and motivation for research beyond the scope of this article). Studies by numerous analysts from Jung to the present day have demonstrated that images are able to communicate beyond the expressive ability of oral or written language. Pinker (1997) demonstrates how this interior communication may occur in the mind, and Berger (1972) has shown how this super-expression can be used to position and manipulate the viewer: from Christ on the cross straight down to the Marlboro Man, a picture often really is worth a thousand words, and because of the image's nonrational, nonlogical nature, can be even more difficult to challenge than printed or verbal positioning. Indeed, although his positing of critical discourse analysis is focused principally on verbal and written language, Fairclough (1989) is insistent about the importance that images have in positioning, either as support for text or on their own: "Not all photographs are equal: any photograph gives one image of a scene or person from among the many possible images. The choice is important, because different images convey different meanings" ( $p$. 52).

As well, the images used in ESL texts have been included through the complex process of bringing an ESL text to market: produced by one (or more) person(s) - the artist or photographer; selected by the author(s) and/or the editors; altered or substituted by editors; and presented in particular juxtapositions through the decision-making of any number of editorial contributors to the final text for any number of socioeconomic reasons. Bell (1991) has demonstrated how this kind of multivoiced authorship can shape and transform the final text message to the point where it is all but unrecognizable to its attributed author; the images, in other words, are subject to the pressures detailed by Bell regarding the collaborative 
production of texts and provide a possible second reading to Bakhtin's (Sola \& Bennett, 1994) statement on the multiplicity of "voices" in discourse: "it [language] is populated-overpopulated-with the intentions of others" ( $p$. 120).

The analysis of images addresses the use of poststructuralist analytical techniques in deconstructing universal truths. The image per se would seem to be the perfect instrument for an Enlightenment dogma, difficult to disintegrate, difficult to challenge on a rational basis; we are forced, when analyzing an image, to discuss feelings and impressions rather than point and counterpoint, and this latent quality is the image's communicative strength. Examples abound, from (again) Christ to the fleur-de-lis to the US flag, all of which can be seen to constitute, in Fax's (1990) words, "neutral and universalizing façades" (Blair \& Holland, 1995, p. 145). The deconstruction of these façades is the prime motivation for the employment by a feminist politics of postmodern, poststructuralist analyses, and the universality of images presents a likely target for research.

\section{The Analytical Technique}

In Language and Power, Fairclough (1989) demonstrated the structure and potential usages of an analytical technique that he referred to as critical discourse analysis (CDA) and that has been applied widely since (Pennycook, 1994; Fairclough, 1995). In essence this technique constitutes an interrogation of discourse, be it dialogue, journalism, advertising, or any other communication, to reveal power- and/or gender-based positioning that might not be easily identifiable at first glance. The technique involves three stages: Description, Interpretation and Explanation, the first stage being a series of 10 questions to be asked of the discourse, with relative subqueries:

Vocabulary

Grammar

Textual Structures
1. What experiential value do words have?

2. What relational value do words have?

3. What expressive values do words have?

4. What metaphors are used?

5. What experiential values do grammatical features have?

6. What relational values do grammatical features have?

7. What expressive values do grammatical features have?

8. How are simple sentences linked together?

9. What interactional conventions are used?

10. What larger-scale structures are there? (Fairclough, 1989). 
Fairclough (1989) states that although his focus is on the verbal element in communication, visual images play an increasing role in a modern society's communicative life: "very often visuals and 'verbals' operate in a mutually reinforcing way which makes them very difficult to disentangle" (p. 28). In Ways of Seeing Berger (1972) makes a convincing case against the use of images in contemporary advertising (and indeed much of Western art from Raphael on) as instruments of oppression with the primary objective of positioning women. It is noted above that the visual element has become increasingly predominant in ESL teaching materials, and it is felt that an adapted version of CDA - critical image analysis-to interrogate these images is justified and appropriate. Thus a series of seven questions was formulated on the basis of the focus of CDA as follows:

1. What is the activity of the image(s)?

2. Who is active (the "protagonist") in the image?

3. Who is passive (the "receiver") in the image(s)?

4. Who has status in the image(s)?

5. What does the body language communicate?

6. What does the clothing communicate?

7. Where are the eyes directed?

Each of these seven queries performs a specific function in the analysis: the first establishes a field of activity for the image, information that can help to determine what areas of gender interaction are being focused on and what areas are being ignored; queries $2-4$, simplistic as they are, obtain a one-word answer-for the purposes of this study, male or female. This creates the possibility of future analysis of ESL texts on a larger scale for quantitative research data in Canadian, US, or other markets, as opposed to the British texts used here. In the second subset, queries 5-7 require a more subjective interpretation of the image, providing impetus for deconstructive discussion of how seemingly innocuous images can reinforce gender positions.

\section{Caveat}

The examination and interpretation of an image is subjective. It must be acknowledged that the interpretations and results of this analysis may well have been quite different under different eyes, an inevitable factor in qualitative research; in other words, "People researching and writing about social matters are inevitably influenced in the way they perceive them ... by their own social experiences and political commitments" (Fairclough, 1989, p. 5) These pressures on researchers, subject to positioning themselves, are probably inevitable; however, Lather (Holland \& Blair, 1995) has postulated an appropriate and effective "third way" between quantitative and qualitative research methodologies, embracing all methods of research into what she terms praxis, "a research paradigm openly committed to critiquing the status quo and building a more just society." The scope of this article required a predominantly qualitative approach. However, quantitative data 
are obtainable; with a simplified set of critical image analysis queries and the vast number of ESL materials currently on the market, further studies could (and should) be done to obtain a global perspective on the issue and to provide the numbers that make quantitative data politically effective.

\section{Data}

The images selected for analysis were drawn from various ESL texts widely available on the market including the award-winning Headway series (Soars \& Soars, 1989) and 4th Dimension (O'Neill, 1986, see Appendix for a complete bibliography of images analyzed and a brief description of each image). The texts were chosen from the full range of teaching levels and from various publishing houses. Again, the number of texts available is far beyond the scope of this report, and selection was necessarily based on my perception (supported by market information) of "popular" or "successful" texts. Other researchers might well choose other texts and obtain different results. These texts were chosen because I had been provided all of them in my work as an ESL teacher in Japan, Canada, and Italy, and they are all currently used or have been used extensively by ESL schools in the UK and other European countries. It may be perceived that the Oxford University Press is overrepresented in this selection, but the market reality has been mirrored. Cambridge publications such as International Exchange (Richards, 1988) demonstrate, however, that the the trend in increased image usage might appear to be universal among the principal publishing houses.

Because the images in the selected texts are too numerous for usable data, a method of culling was employed: the only images analyzed were those that juxtaposed, either in a single photo or in collage, men and women, as it is my experience that men and women presented alone were presented in different ways (a potential subject for further study). This culling produced 35 images for interrogation (see Appendix).

\section{Results}

\section{What is the activity of the image(s)}

By splitting the collages it was determined that these 34 image presentations actually contained 76 single images; 65 men were presented in a principal role, as opposed to 59 women, without taking crowd scenes into account. The focus of the images was overwhelmingly on the work environment at $41 \%$. Next followed fashion at $20 \%$ and entertainment at $13 \%$. Where travel clearly concerned business, it was classed as work; where travel was clearly a vacation or free-time activity, it was classed as entertainment.

These numbers demonstrate the emphasis of ESL texts on particular spheres of human activity, the balance. of which may or may not be applicable or appropriate in the target ESL market. There was, for example, no trace of religion or any other field of a morally engaging matter, apart from one image dedicated to Third World assistance (see below). In the work-re- 
lated images the manager, leader, or protagonist of the image was consistently a man. The images dedicated to fashion, however, had a consistent majority of women. Again, this balance had the effect of placing men and women firmly in one or the other sphere at an almost subliminal level. Many other fields of activity were conspicuous by their absence: politics, for example, and, interestingly, formal study.

\section{Who is active in the image?}

In $76 \%$ of the images the man was given an active role; the women in $24 \%$. This means that for the ESL texts (and so for the students throughout the world being taught, in this case, British "culture" along with the language), men are the protagonists, the doers. In only one field of activity was this proportion reversed: fashion.

\section{Who is passive in the image?}

As might be expected from the above, women were given the passive role in $75 \%$ of the images, the men in $25 \%$. This, as above, provided reinforcement for the idea that women are the receivers; it is worth noting that where men were portrayed in a passive role, the context of the image ensured that their status remained intact.

\section{Who has status in the image?}

Status can be conferred by physical stature, by the perspective of the portrayer (in this case usually a photographer), by accessorization (clothing, desks, etc.), and by the degree to which others serve. Following this definition, it was seen that in fully $89 \%$ of the images men were given higher status than women. Usually this occurred as a function of employment: there were no male receptionists, for example, and no women leading seminars. Sometimes, though, the work of the photographer assisted in elevating the status of men; by positioning women behind the men's shoulders, for example, Image 1,2, or by cropping and pasting more than one image (Image 5).

\section{What does body language communicate?}

The trends that showed up in the data verged on clichés (which does not, of course, detract in any way from their communicative power): often images of the men communicated a combination of relaxation in the face of danger with concentration in the work environment. In the few instances where men had the passive role in an image, they gained status by a relaxed, even disdainful physical attitude. Women were generally depicted in such a way that their shorter stature was highlighted, and the hands were often crossed in the lap, a gesture Morris (1977) terms "genital barrier."

As well, the position of the women's heads in these images was usually inclined, often toward the man, an attitude indicating submission (Morris, 1977). In the images concerned with fashion, the men were without exception portrayed in a relaxed, confident posture; the women were supporters to 
men or, if portrayed alone, took on a kind of exotic otherworldliness. Berger (1972) argues that this dichotomy exists in art throughout Western history: men are depicted as the subject of envy; women are depicted as objects to be desired and possessed. See below for a comment on eye direction.

\section{What does the clothing communicate?}

As mentioned above, there is a fundamental difference in how men and women were presented from a sartorial point of view. Even in the large percentage of images dedicated to fashion, men were presented with three basic modes: casual, professional, and power-dressed. Women, on the other hand, were presented in baroque period dresses, futuristic lamé, "fun" clothing that at times attained the bizarre, and the somewhat disturbing image of Lady Diana removing a cloak or shawl before a bank of photographers (Image 11). Photographed (caught?) from behind, Diana is facing a blazing bank of lights and paparazzi flashes as she slips a cloak from her bare shoulders; she appears to be naked, although one trusts she is wearing a strapless gown. These kinds of images position women not only as "more interested in fashion," but also as mannequins, objects to be observed (Berger, 1972).

\section{Where are the eyes directed?}

In several of the images men and women directed their eyes toward each other; however, in most cases the man added a smile or other gesture that removed any trace or intimacy or weakness from the contact (see Images 3, 7, $12,27)$. In every case where a man looked at a woman and she looked elsewhere, tension, ridicule, or anger could be identified in the man's physical attitude. More often images with both a man and a woman could be seen to portray men looking off into the distance while women looked at them: usually up at them. Again, this is a photographer's trick that enhances the statural difference between them and creates a sense of dependence or need on the part of the woman, strength and determination, "important things to $\mathrm{do}^{\prime \prime}$ on the part of the man. Often in the collages, however, images were found of women alone gazing directly into the camera (Images 12, 18, 33). These images all had to do with fashion or television entertainment and created a different kind of rapport with the viewer. As Berger (1972) noted,

The essential way of seeing women, the essential use to which their images are put, has not changed. Women are depicted in a quite different way from men-not because the feminine is different from the masculine-but because the "ideal" spectator is always assumed to be male and the image of the woman is designed to flatter him. (p. 64)

\section{Ramifications}

The teaching practices themselves represent particular visions of the world and thus make the English language classroom a site of cultural 
politics, a place where different versions of how the world is and should

be are struggled over. (Pennycook, 1994, p. 146)

It would seem, even from such a brief analysis as that done for this project, that gender positioning by means of selected image reproduction is an inherent component of the production of ESL materials. It is possible that this positioning could be reinforced by ESL teachers through the use and dissemination of these materials - not that such reinforcement must definitely occur, but that it could: the principal issue is empowerment, of both ESL students and their teachers.

It can be predicted that the results of this analysis could be replicated with a fair degree of accuracy from a sampling of 350 (or 3,500) images, as opposed to the 35 analyzed. Indeed, I believe that further research using queries 2-4 on a quantitative basis might well provide incontrovertible numbers that could prove effective in bringing industrial pressure to bear on publishing houses to reflect a less distorted reality. The use of images in ESL texts to communicate a particular culture and a particular "commonsense" about the world has grown exponentially since the 1970s, a trend that can be expected to continue and that needs to be addressed by ESL teachers (and text publishers) worldwide. It also needs to be borne in mind that although a particular vision of men and women has been identified in the positioning of these images (men as strong, active, in control; women as submissive, fashionoriented, controlled), these are not the only dogmas being communicated. Along with gender positioning, there is a specific socioeconomic "norm" in evidence: work is the primary focus, specifically, making money, followed by the use of that money for consumption and diversion. As Brown (1990) notes, these texts "assume a materialistic set of values ... international travel, not being bored, positively being entertained, having leisure, and, above all, spending money casually" (p. 13). The myriad human discourses left outside this closed patriarchal and capitalist circle are not deemed worthy of (in this case) British culture, the propagation of which has been, as noted, the hidden (and not so hidden) agenda in the ESL industry from the outset. As Fax (Blair \& Holland, 1995) notes, "Any episteme requires the suppression of discourses that threaten to differ with or undermine the authority of the dominant one." The images used to support the ESL materials studied here would seem to be an effective instrument in that suppression.

\section{Taking It Further}

As an analytical tool, I believe that critical image analysis is effective in revealing broad trends in gender positioning in ESL texts that might otherwise remain at a hidden or subliminal level. The instrument itself is simple enough to be used as an interrogative tool by teachers facing ever-new editions of ESL texts, and would seem to respond to criticisms of both qualitative and quantitative methodologies as it employs both and obtains 
varied types of data. More research needs to be done in the Canadian, US, Australian, and other markets where ESL materials are produced in order to challenge the potential criticism that this is a British ESL text issue. Further, the subjective nature of image analysis opens the research to academic dismissal (Kouritzin, 2000; Fairclough, 1989)-there is a need for replication of this study if the results are to be considered valid in a wider academic or political context.

Undoubtedly numerous ESL teaching professionals are actively engaged in deconstructing the texts marketed for their use in the classroom and challenging the assumptions conveyed by those texts. I hope that tools such as critical image analysis (and the instrument from which it was derived, critical discourse analysis) can provide further means of challenging the "reality" communicated by ESL texts and provide support to ESL teachers in their efforts to avoid reinforcing these gender positions on a global scale.

\footnotetext{
Notes

${ }^{1}$ Valuable future research might try to identify different presentations of "reality" in ESL texts produced for foreign consumption as opposed to texts used "at home" in UK (or US or Canadian) schools, the latter potentially being designed to "keep $x$ in his/her place" (Siraj-Blatchford, 1995) and the former being a presentation of gender and other realities as an intrinsic part of the language itself.

${ }^{2}$ As discussed below, note that the attributed author often has little or no control over the images used in any particular text, final decisions usually being a matter of "editorial prerogative" (Bell, 1991).

${ }^{3}$ See the home page of Dave's ESL Café (www.eslcafe.com) for a demonstration of this: a banner ad guarantees "teaching and traveling" for "lowest cost ... [and] ... highest quality!" (www.eslcafe.com/joblist). The banner links to a school offering three-week CTEFL certification courses (4 weeks for the "comprehensive" course) and lists as a "course fact" that "no second language, teaching or computer experience is necessary."
}

\section{The Author}

Peter Giaschi was born in Huntsville, Ontario, and has taught ESL in Canada, Japan, China, and Italy. He currently lives in Bergamo, Italy, where he teaches at a high school and consults for several multinational firms.

\section{References}

Achebe, G. (1975). English and the African writer. In A. Mazrui (Ed.), The political sociology of the English language (pp. 216-233). Paris: Mouton.

Bell, A. (1991). The language of news media. Oxford, UK: Blackwell.

Berger, J. (1972). Ways of seeing. London: Penguin.

Blair, J., \& Holland, M. (Eds.). (1995). Identity and diversity. Clevedon, UK: Multilingual Matters.

British Council. (1959-1960). Annual report. London: Author.

Brown, G. (1990). Cultural values: the interpretation of discourse. ELT Journal, 44(1), 11-17.

Coombs, D. (1988). Spreading the word: The library work of the British Council. London and New York: Mansell.

Crystal, D. (1988). The English language. Harmondsworth, UK: Penguin.

Ellis, D. (1990). Cross-cultural relevance in EFL materials. Paper presented at AILA '90, Thessaloniki.

Fairclough, N. (1989). Language and power. London: Longman. 
Fairclough, N. (1995). Critical discourse analysis. London: Longman.

Fisher, E. (1994). Distintive features of pupil-pupil classroom talk and their relationship to learning. In B. Stierer \& J. Maybin (Eds.), Language, literacy and learning in educational practice (pp. 157-175). Clevedon, UK: Multilingual Matters.

Hartley, B., \& Viney, P. (1979). American streamline. Oxford, UK: Oxford University Press.

Kouritzin, S.G. (2000). Bringing life to research: Life history research and ESL. TESL Canada Journal, 17(2), 1-35.

Mercer, N., \& Swann, J. (1996). Learning English: Development and diversity. London: Routledge.

Morris, D. (1977). Manzwatching. London: Grafton.

Mukherjee, T. (1986). ESL: An imported new empire? Journal of Moral Education 15, 43-49.

Pennycook, A. (1994). The cultural politics of English as an international language. London: Longman.

Pinker, S. (1997). How the mind works. New York: Norton.

Prodromou, L. (1988). English as cultural action. ELT Journal, 42, 73-83.

Richards, J.C. (1988). Interchange. Cambridge, UK: Cambridge University Press.

Schenke, A. (1991). The "will to reciprocity" and the work of memory: Fictioning speaking out of silence in ESL and feminist pedagogy. Resources for Feminist Research, 20(3-4), 47-55.

Siraj-Blatchford, I. (1995). Racialized and gendered discourses in teacher education. In Dawtrey, Holland, \& Hammer (Eds.), Equality and inequality in education policy (pp. 242-259). Clevedon, UK: Multilingual Matters.

Sola, M., \& Bennett, A. (1994). The struggle for voice: Narrative, literacy and consciousness in an East Harlem school. In J. Maybin (Ed.), Language and literacy in social practice (pp.

117-138). Clevedon, UK: Multilingual Matters.

Soars, L., \& Soars, J. (1989). Headway. Oxford, UK: Oxford University Press.

\section{Appendix: Image Sources}

Images 1-4: Soars, L., Soars, J. (1991). Headway pre-intermediate. Oxford: Oxford University

Press. (1: p. 19; 2: p. 44; 3: p. 67; 4: p. 79)

Image 1: This image is a photograph linked to a "Real Life Drama" story of a couple who survived a maritime disaster. Both man and woman are seated; the man smiles to the left of the camera while the woman, a worried expression on her face, gazes into the camera. Her right arm is behind the man's back and her left hand rests on his thigh.

Image 2: A photograph of the Sultan of Brunei and his first wife. He strides toward the camera, gazing to his left, his left hand on his belly. She follows, gaze lowered and to the right.

Image 3: A photograph linked to a fictional conversation between a man and woman; she is leaving for work, he is staying at home; he has a barbecue apron on, his right hand on her shoulder, and smiles reassuringly; she looks up at him (he is a clear $20 \mathrm{~cm}$. taller), her hand on his waist, her look pensive/worried.

Image 4: A collage of three photographs linked to a passive voice exercise regarding nylon. The uses of nylon are demonstrated in the photographs by (a) two pairs of women's legs cut off at crotch level, the shoes somewhat flowery/bizarre, the dresses very short; (b) a man at work on a gigantic carpet loom; and (c) a man descending with a nylon parachute.

Images 5-10: Soars, L., \& Soars, J. (1996). New headway intermediate. Oxford: Oxford University

Press. (5: p. $16 ; 6:$ p. $57 ; 7:$ p. $65 ; 8:$ p. $73 ; 9:$ p. $78 ; 10:$ p. 107)

Image 5: A cut-and-paste "photograph" linked to a story entitled "The Happiest Person In Britain." An evidently British man is pasted into the foreground wearing a pinstripe suit, right hand in pocket, left hand on the leash of his golden retriever, smiling broadly. Behind him is the cut-and-paste photo (much smaller) of a woman with two children, her hands on a shoulder of a girl and boy, in front of a cut-and-paste two-story home. 
Image 6: A two-photo collage linked to a fictional story of two girls talking about one's French exchange visitor, just arrived. The smaller photo shows the (apparently) French girl smiling into the camera. The principal photo shows the family unit greeting the same girl as she disembarks from the Eurostar train: man in the middle (father), woman (wife) on right holding onto son, daughter on left greeting the visitor.

Image 7: A photograph linked to Unit 7: "The World of Work." A female job applicant sits beside a desk speaking to a man whose desk it is; she is the applicant. He smiles broadly, right hand on her "file," left hand on his thigh. She fixes him with a half-smile, speaking.

Image 8: A photograph linked to a listening comprehension exercise entitled "Thomas Wilson: A Retired Man." In the photograph a young girl deemed to be a granddaughter cradles her face in her hands as she looks up at an elderly man in the act of discourse.

Image 9: A complex collage linked to the presentation of the 2nd conditional tense (in this case: "If I had $£ 2,000,000$ "); there are eight photographs in this collage, starting with two upper photographs showing two boys, the boy on the left of (possibly Indian) ethnicity, the boy on the right Caucasian; below these two are a photo of an older Caucasian boy and a photo of a Caucasian couple mid-20s-she smiles, he does not. Directly below these are photos of two men. On the left is a casually dressed 30-something man smiling off to his right; on the right (at the bottom of the collage) is a smiling Caucasian man in a pinstripe suit gazing directly into the camera. Attached to the penultimate photo are two photos of women off to the left of the page, both smiling or gazing into the camera.

Image 10: A photograph of the (apparent) interior of a British Tourist Information office, linked to a fictional conversation regarding "what Rosie wants to know." In the photo the man behind the counter is looking at the material in Rosie's hands and speaking. She looks at the material in her own hand. Behind her a male client waiting his turn looks at a pamphlet.

Images 11-12: Soars, L., \& Soars, J. (1989). Headway advanced. Oxford: Oxford University Press.

(11: p. 110; 12: p. 62)

Image 11: A complex collage of four photographs linked to a listening comprehension exercise regarding Nigel Dempster, evidently "a journalist who writes the most famous gossip column in Britain." The collage begins on the upper left with a photo of Mr. Dempster; in a clockwise direction follow a photo of older women gazing at Princess Diana while she holds flowers and comments to someone on her left; a photo of Prince Charles and Princess Diana before a bank of photographers, somewhat distanced: she is removing a cloak or shawl and one can see only bare skin beneath it; a photo of a bank of photographers, evidently waiting for Princess Diana.

Image 12: A complex collage of eight photographs linked to a section entitled "Your Taste In Clothes." Starting clockwise from the upper left we see: (a) a photo of a young man and woman on stools looking at each other; he scratches his head, she smiles with chin cupped in hand; (b) an older woman laden with various shopping bags walking on the street; (c) a young woman in a dramatic pose gazing into the camera dressed in a kind of black plastic; (d) two young women apparently jogging, smiling at the camera, dressed in exaggerated "Disneyish" jogging suits; (e) an older woman holding a potted plant in her hand, dressed in what can only be described as an alien manner; ( $f$ ) a young man dressed in a luxury/fashion style, hands in pockets, striding, gazing unsmiling into the camera; $(\mathrm{g})$ a youngish woman, dressed in an extremely luxurious style before the gates of a manor, gazing into the camera; $(h)$ a young man apparently involved in Union Council elections gazing thoughtfully into the camera.

Images 13-24: Taylor, L. (1996). International express pre-intermediate. Oxford: Oxford University

Press. (13: p. 9; 14: p. 25; 15: p. 32; 16: p. 44; 17: p. 49; 18: p. 56; 19: p. 72; 20: p. 85; 21: p. 88;

22: p. 99; 23: p. 104; 24: p. 112)

Image 13: A photograph linked to a business meeting between a translator (female) and wine expert (male) as they arrive for a wine trade fair. The two smile at each other, framing a young woman (airport employee?) who smiles and gazes at the man. The woman has four pieces of luggage on a trolley, the man one bag and an overcoat. 
Image 14: A photograph linked to "business English" showing the man from Image 13 above speaking to an office receptionist (female). He stands relaxed in front of the desk, briefcase in hand, smiling down at the receptionist; she, seated, smiles at the man and extends a welcoming hand.

Image 15: Two photographs showing the same man checking into a hotel. The receptionist is female. She stands with hands folded in front of her, smiling at the man. He does not smile: in the first frame he is evidently hurrying into the hotel, in the second, signing the register.

Image 16: A three-quarter-page photograph of the man and woman from Image 13 seated in a luxurious restaurant. He has a menu but does not look at it, rather gazing down at the woman; she has a menu open but looks at the man. Neither smile.

Image 17: A photograph linked to a "job interview" exercise. The applicant, a woman, sits at a table with her hands crossed in front of her, gazing at the man. He looks at her unsmilingly and takes notes.

Unit 18: A collage of four photographs linked to Unit 7: "Working in Another Country." All the images are concerned with fashion; clockwise from upper left: (a) a man and woman walking along a street disturbing pigeons as they go. Both are smiling broadly, dressed in "traditional" British luxury clothing (Burberry, Harris, etc.). The man walks a step in front of the woman; (b) a female model on a fashion-show runway; the clothes are futuristic, in a kind of silver lamé; she gazes aggressively into the camera; (c) a photograph of a young woman in a pseudo-baroque dress in a period setting; she has one hand on the back of a semi-clad statue and gazes into the middle-left distance; (d) a smaller photograph of a female fashion designer working at a desk.

Image 19: A collage of four photographs linked to "Air Travel." The bottom two photographs show airport crowd scenes; the upper two photographs show check-in and boarding. In both upper photographs the travelers are white men in business attire, the check-in/boarding attendants young women.

Image 20: A collage of train station signs, interesting in that two of the photographs are of signs pointing to the "Ladies" room.

Image 21: A half-page photograph linked to "a conversation between Duncan Ross and his secretary Carol." He sits on the edge of a desk, waving eyeglasses in his right hand, gazing toward the camera and speaking. She is seated (primly?) behind and below him taking notes on a steno pad, smiling up at the back of his head.

Image 22: A photograph linked to "Social Customs." A seminar is being given by a "British manager" to a group of professionals: four men and two women. One of the women is laughing as she takes notes, the other gazes at the seminar leader (a man). None of the male participants smiles.

Image 23: A collage of four photographs linked to a "Body Language" exercise. From upper-left: two young boys of African/Caribbean ethnicity dressed in sailor costumes, arms around each other's shoulders, smile broadly into the camera; two female employees of a café gaze angrily at each other, arms crossed in front of them; an older man of Indian (?) ethnicity in luxurious surroundings smiles at someone to his right; a young man and woman outdoors: he is positioned in front of the woman with a newspaper in his hand and looks off to the middle-right; she smiles broadly at him from behind his shoulder, offering him a pencil.

Image 24: The "wine expert" and "translator" from Image 13 above together with "Duncan Ross" from Image 21. The woman is in the foreground, seated on the passenger side of an open convertible; she leans back against the headrest, left hand on her breast, smiling off into the distance. Behind her on the steps of a palatial residence the two men look over at her and smile.

Images 25-29: O'Neill, R. (1986). 4th dimension. London: Longman Group. (25: p. 23; 26: p. 25;

27: p. 30; 28: p. 36; 29: p. 84)

Image 25: Two images linked to Unit 3 ("Love"). On the left is a young professional woman described as "very good at her job" sitting at her desk looking to the left of the camera, speaking 
and gesturing. On the right is a middle-aged man described as a "successful lawyer" seated at a desk, chin propped on his folded hands, staring grimly to the right of the camera.

Image 26: A single image linked to "when Dennis found out that Cynthia had been seen with an old boyfriend." The man from Image 25 and another woman are seated at a café table. He is clearly angry, stares at her and speaks. She, clearly contrite, stares into her coffee cup.

Image 27: A bi-page image of three young people before a late-model car; on the left two women discuss something, one speaking, the other looking back at her, neither smiling. Behind them, leaning an arm on the hood of a car, a jacket draped casually over his shoulder, a young man looks at the two women and smiles broadly.

Image 28: A collage of three photographs showing various professions. From the top: (a) "Jean, a social worker" shows a middle-aged woman seated at a desk, smiling back at the camera, in her left a newspaper; (b) "Martin, an accountant" shows a young man seated at a very large desk, phone tucked under an ear, pen in hand, looking at some papers; (c) "Robert, an artist" shows a middle-aged man smiling directly into the camera (these last two images have been found in various other ESL texts from other publishing houses, which implies the existence of a central image bank used by various publishers).

Image 29: A simplistic pen-and-ink rendering of a doctor (male) and a nurse (female) in discussion. They look at each other, the height difference is minimum $20 \mathrm{cms}$.

Images 30-33: Soars, L., \& Soars, J. (1987). Headway post-intermediate. Oxford: Oxford University

Press. (30: p. 18; 31: p. 21;32: p. 70; 33: p. 94)

A collage of four photographs linked to a discussion of "Vocations." From top (a) a man walking on the summit of a mountain; (b) three male crew (pilot, co-pilot, navigator) in the cockpit of a Boeing 747; (c) Tina Turner, a "world famous singer"; (d) a youngish nun ("Sister Andrea") holding and smiling at a young African girl.

Image 31: A complex collage of eight photographs linked to a discussion of "the qualities needed ... in a profession." From top: (a) a young female technician of Asian ethnicity adjusting a gauge; (b) a male scientist working in a laboratory; (c) a male manager dictating to his secretary; (d) a male pediatrician speaking to a mother and child; (e) a male mathematics (?) teacher demonstrating a procedure to a group of students; $(f)$ an elderly female librarian taking a book from a young customer; $(\mathrm{g})$ a group of eight male photographers all snapping pictures of something or someone out of frame; (h) a young female window-dresser arranging clothes in a modern store window.

Image 32: A collage of five photographs linked to an exercise on "describing people." Top: a period photo of a family seated for their portrait (patriarch, mother, six children); middle-left: a middle-aged professional male seated at a restaurant table making notes in an agenda; middleright: a 30-something wealthy female trying on a dress in a clothing store; lower-left: a casually dressed young woman leaving a building with some books under her arm, smiling directly into the camera; lower-right: a young professional man at a computer terminal.

Image 33: Two photographs linked to a discussion of "the advantages and disadvantages of being rich and famous." Both images are taken from the US television series Dynasty. Top: John Forsythe smiles into the camera, his hands on the shoulders of Linda Evans, seated before him and likewise smiling into the camera; bottom: a close-up portrait of Joan Collins gazing directly into the camera.

Image 34: Cotton, D. (1984). World of business. London: Unwin Hyman. (34: p. 1).

A three-quarter-page photograph of a "modern office." In the foreground a middle-aged male inputs data into a computer. In the background a professional male has just opened the office door and is looking down at a female secretary, who speaks on the phone with right hand in dress pocket. 